\title{
OUTWARD FOREIGN DIRECT INVESTMENT AND DOMESTIC INVESTMENT: EVIDENCE FROM INDUSTRALIZED ECONOMIES USING PANEL DATA
}

\section{ANALYSIS}

\section{WAQAR AMEER \& HALWAN MUSAAD MANSOUR. A}

School of Economics and Trade, Hunan University, Yuelushan, Changsha, Hunan Province, People's Republic of China

From 1970-2013, Industrialized countries, which are them an in world economies, had domestic investment and had positive long-term effects on outward foreign direct investment. The group-mean estimator for the coefficient on DI is 4.56, suggesting that one dollar increase in DI increases OFDI by 4.56 dollars. Our results suggest that increased outward foreign direct investment is a consequence and cause of increased domestic investment.
\end{abstract}

KEYWORDS: Outward FDI, Domestic Investment, Co Integration, Panel Data \& Industrialized Economies

Received: Jul 05, 2017; Accepted: Jul 22, 2017; Published: Jul 29, 2017; Paper Id.: IJECRAUG201710

JEL Classification: F21; F23; C23

\section{INTRODUCTION}

Recent empirical and theoretical studies have mainly focused on the impact of foreign direct investment (FDI) inflows on economic growth. Some studies (Zhang (2001), Liu et al. (2002) and Herzer and Schrooten (2008)) have explored the direction of causality between economic growth and FDI outflows. The question of whether and how the outward foreign direct investment (OFDI) affects domestic output or domestic investment is the subject of public debate in industrialized economies. Desai et al. (2005) argues that a higher OFDI is associated with higher levels of domestic investment .OFDI allows firms to import raw material from foreign affiliates at less expensive rates and generate exports of intermediate goods used by foreign affiliates. Industry combines home production with firms abroad to reduce the cost of production, and economies of scale thus increase their domestic output and domestic investment.

Here, we explore how domestic investment affects OFDI in major world economies. Herzer and Schrooten (2008) argue using time series data that OFDI has positive long-term effects on domestic investment in the United States (US), but Germany has a complementary relationship in the short-term .Limited research has investigated the relationship between domestic investments on outward FDI using panel data. Therefore, we further explored this area by determining the relationship between the domestic investment and OFDI using panel data to bridge this shortcoming in the literature. We used co integration and causality analysis of the G20 over the time span of 19702013.Our findings are as follows: (1) there is positive long-term relationship between domestic investment and OFDI; and (2) long-term causality is unidirectional, suggesting that increased outward foreign direct investment is a consequence and cause of increased domestic investment. 
The paper is organized as follows: Firstly, we describe data and methodology, then present the empirical results, causality test analysis and finally is the conclusion.

\section{DATA AND METHODOLOGY}

After evaluating previous published research and panel co integration studies, we found a bivariate long-term relationship as follows:

$$
\mathrm{OFDI}_{i t}=a_{I}+\beta \mathrm{DI}_{i t}+\varepsilon_{i t}
$$

Where, $i=1,2,3, \ldots, N ; t=1,2,3, \ldots T ; D I$ is the domestic investment of country $i$ in year $t ; O F D I$ is outward foreign direct investment of the country $i$ in year $t$; and $\varepsilon$ is the error term. The proxy for domestic investment $(D I)$ is defined as the gross capital formation (GCF) ratio of GDP. GDP was measured using constant 2005 US dollars. We used the net OFDI rather than the gross OFDI because the gross FDI figures reflect the sum of the absolute outflow and inflow values in the balance of payment financial accounts, and thus do not take into account disinvestment. Because the net outflows have negative values in some years, it is not possible to use logarithms. Thus, it is common practice in research to use the net FDI as a percentage of the GDP to derive economically interpretable results. Data on the net FDI outflows as a percentage of the GDP is taken from the UNCTAD FDI database, and the GDP at constant US dollars using 2013 World Development Indicators. The sample consists of industrialized economies over the time period of 1970-2013.The countries included were Argentina, Australia, Brazil, Canada, France, India, Italy, Japan, Mexico, South Africa, South Korea, United Kingdom and the US. The list of industrialized countries that were not included because of missing data were China, Germany, Indonesia, Russia, Saudi Arabia, Turkey and European Union.

\section{EMPIRICAL RESULTS}

We first estimated Equation (1). Levin et al. (2002) and Im et al. (2003) panel unit root tests suggest that our variables DI and OFDI are non-stationary at levels and stationary at the first difference. Our unit root tests in Table 1 suggest that these integrated variables are of the same order. Therefore, we used co integration methodologies for the purpose of estimation.

Table 1: Panel Unit Root Tests for Dependent and Independent Variables

\begin{tabular}{|l|c|c|c|c|}
\hline Unit Root Procedure & LLC & IPS & LLC & IPS \\
\hline \multicolumn{3}{|c|}{ Levels } & \multicolumn{2}{c|}{ First Differences } \\
\hline OFDI & 3.9 & 1.77 & $-5.76^{* * *}$ & $-15.98^{* * *}$ \\
\hline & $(1.00)$ & $(0.96)$ & $(0.00)$ & $(0.00)$ \\
\hline DI & -0.98 & -1.13 & $-22.95 * * *$ & $-20.44 * * *$ \\
\hline & $(0.16)$ & $(0.12)$ & $(0.00)$ & $(0.00)$ \\
\hline
\end{tabular}

Note: LLC, Levin, Lin and Chu; IPS, Im, Pesaran and Shin; p-values are in parentheses;***, ***, * indicate that the null hypothesis is rejected at 1, 5 and 10 percent, respectively.

We first tested for co integration using the Pedroni (1999) approach. Seven test statistics are used to test the residuals for stationary. Four of these test statistics combine the autoregressive coefficients across different countries during the unit root test, and thus restrict the first-order autoregressive parameters to be the same for all countries. Pedroni (1999) refers to these statistics as panel co integration statistics. The other three statistics are based on averaging the individually-estimated autoregressive coefficients for each country. Accordingly, these statistics allow the autoregressive coefficients to vary across countries and they are referred to as the group-mean panel co integration statistics. The first of 
the panel co integration statistics is a non-parametric variance ratio test. The second and third are panel versions of the Philips and Perron (PP) rho- and $t$-statistics, respectively. The fourth statistics is a panel Augmented Dickey Fuller (ADF) F statistic that is analogous to the Levin et al. (2002) panel unit root test. Similarly, the first two group-mean panel co integration statistics are panel versions of the Philips and Perron rho- and $t$-statistics. The third is a group-mean ADF test similar to the Im et al. (2003) panel unit root test.

As an additional test for co integration, we used the Larsson et al. (2001) statistics based their test on theJohansen (1988) maximum likelihood estimator, which avoids the use of unit-root tests on the residuals and relaxes the assumption of a unique co integrating vector. Thus, this model allows us to test for more multiple co integrating vectors. Let LR denote the cross-section specific likelihood-ratio (trace) statistics of the hypothesis that are at most $r$ co integrating vectors in the system. The standardized LR-bar statistics are reported below:

$$
\psi_{\overline{L R}}=\frac{\sqrt{N}[\overline{L R}-\mu]}{\sqrt{v}}
$$

Where, $\overline{L R}$ the average of the trace statistics is for each cross-sectional unit, $\mu$ is the mean and $v$ is the variance of the asymptotic trace statistics (a model with a constant but no trend in the co integrating relationship).

Table 2: Pedroni (1999) Panel Co integration Test

\begin{tabular}{|l|c|c|}
\hline \multicolumn{1}{|c|}{ Pedroni(1999) } & Panel Co Integration Statistics & Group-Mean Panel Co Integration Statistics \\
\hline Variance ratio & $0.47(0.31)$ & $-5.55^{* * *}(0.00)$ \\
\hline PP rho-statistics & $-6.23^{* * *}(0.00)$ & $-5.96 * * *(0.00)$ \\
\hline PP t-statistics & $-6.5 * * *(0.00)$ & $-3.54 * * *(0.00)$ \\
\hline ADF statistics & $-6.85^{* * *}(0.00)$ & all test statistics are \\
***indicates rejecting of the null hypothesis that there is no co integration at a 1\% level. Alt
\end{tabular}
asymptotically normally distributed. The lag numbers are determined using the Schwarz criterion.

Table 2 and 3 report the test results. All tests statistically indicate co integration, suggesting that there is a longterm relationship between $D I$ and OFDI.

Table 3: Johansen-Fisher Panel Co integration Test (The Overall Sample): OFDI, DI

\begin{tabular}{|l|c|c|c|c|}
\hline Hypothesized Number of & (Trace Test) & P-Value & (Max-Eigen Test) & P-Value \\
\hline co integration & & & & \\
\hline relationships & & & & \\
\hline None & $44.09 * * *$ & 0.0148 & $48.77 * * *$ & 0.0044 \\
\hline at most 1 & 13.45 & 0.9795 & 13.45 & 0.9795 \\
\hline
\end{tabular}

Note: Probabilities are computed using the asymptotic Chi-square distribution; p-value are shown immediately to the right of the relevant test statistic; $* * * * *$ indicate that the null hypothesis is rejected at 1, 5 and 10 percent, respectively.

\section{ESTIMATING THE LONG-TERM RELATIONSHIP}

We, then estimated the parameter $\beta$ using the between-dimension, group-mean panel dynamic ordinary least squares estimator, suggested by Pedroni (2001). The Dynamic Ordinary Least Squares Estimator (DOLS) regression is presented as follows:

$$
O F D I_{i t}=a_{i}+\beta_{i} D I_{i t}+\sum_{j=-p_{i}}^{p_{i}} \Phi_{i j} \Delta D I_{i t-j}+\varepsilon_{i t}
$$


Where, $\beta$ is the conventional time series DOLS estimator applied to the $i$ th country of the panel. $\Phi_{i j}$ is the coefficient of lead and lag differences, which accounts for the possible serial correlation and endogeneity of the regressors, thus yielding unbiased estimates. The group-mean panel dynamic ordinary least square estimator for the coefficient $\beta$ is:

$$
\beta=N^{-1} \sum_{i=1}^{N} \beta_{i}
$$

And, the associated $t$-statistics are calculated as:

$$
t_{\beta}=N^{-1 / 2} \sum_{i=1}^{N} t_{\beta_{i}}
$$

The DOLS parameter estimates for the group-mean panel DOLS estimates are reported in Table 4. Both fixed and panel group-mean estimates show a statistically significant positive effect of $D I$ on OFDI. The group-mean estimator for the coefficient on $D I$ is 4.56 , suggesting that one dollar increase in DI increases OFDI by 4.56 dollars.

Table 4: DOLS Approach

\begin{tabular}{|l|c|c|}
\hline & Leads and Lags & Coefficient on $\boldsymbol{D I}$ \\
\hline Panel results & & \\
\hline Group-mean estimator (Pedroni, 2001) & 1 & $4.56^{* * *}(10.2)$ \\
\hline Fixed effects estimators & & $8.05 * * *(5.19)$ \\
\hline
\end{tabular}

$* * *$ indicates significance at the $1 \%$ level; $t$-statistics in parentheses

To evaluate the robustness of the positive relationship between OFDI and DI, we also report the results of the fixed-effect estimators. The fixed-effects results are consistent with the group-mean results. The estimated DI coefficient is positive and highly significant.

\section{TESTING FOR CAUSALITY}

The above interpretation of the estimation results is based on the assumption that long-term causality runs from $D I$ to OFDI. A statistically significant positive coefficient on the DI is necessary for the OFDI to have an impact on $D I$. There is another possibility that DI is determined by the OFDI. Herzer (2008), explains that establishing foreign fir ms incurs extra costs to overcome cultural and social barriers. Only a few firms of a specific size can support these fixed and extra costs and consequently engage in OFDI. Thus, an increase in the domestic output may allow firms to invest more abroad. Co integration between OFDI and domestic investment suggests that vector error correction should be used when testing for Granger causality. We, then investigated the direction of causality. The panel vector error correction model equations are reported below:

$$
\begin{aligned}
& \Delta \mathrm{OFDI}_{t}=\mathrm{h}_{0}+\sum_{i=1}^{n} h_{O i} \Delta \mathrm{D} I_{t-i}+\sum_{i=1}^{n} h_{G i} \Delta O F D I_{t-i}+{ }_{\gamma} \mathrm{ECT}_{G t-1}+u_{1 i t} \\
& \Delta \mathrm{DI} I_{t}=\mathrm{g}_{0}+\sum_{i=1}^{n} g_{o i} \Delta \mathrm{D} I_{t-i}+\sum_{i=1}^{n} g_{G i} \Delta \mathrm{OFDI}_{t-i}+\zeta \mathrm{EC} T_{O t-1}+u_{2 i t}
\end{aligned}
$$

Where $E C T_{G t-l}(6)$ and $E C T_{O t-1}(7)$ are the error correction terms

A significant error correction coefficient indicates that there is long-term Granger causality from independent to the dependent variables, while long-term Granger non-causality is regarded as equivalent. 
Table 5: Results of Granger's Causality Test: Long-Term

\begin{tabular}{|c|c|}
\hline Equation & Coefficient of Error Correction Term (ECT) \\
\hline 6 & $-0.2354 * *(-7.60)$ \\
\hline 7 & $-0.000728(-1.42)$ \\
\hline$* * *$ and $* * *$ indicate statistical significance at $10 \%, 5 \%$ and $1 \%$ levels, respectively; t-ratios
\end{tabular}

are in parentheses

Table 5 shows that the coefficient of error correction term is significant with a negative sign in equation (6).This suggests that our long-term causality is unidirectional from $D I$ to OFDI, which also suggests that increased OFDI can be a cause/consequence of increased $D I$.

\section{CONCLUSIONS}

We have explored a long-term relationship between the $D I$ and OFDI using co integration and Restricted Vector Autoregressive (VECM) econometric methodologies. We found that DI has long-term positive effects on the OFDI. Our results partially agree with the findings of Herzer and Schrooten (2008) and Herzer (2008). Our results indicate that longterm causality is unidirectional, suggesting that an increased OFDI is a cause and consequence of increased DI. Thus, we conclude that OFDI and DI (Domestic investment) are positive and highly correlated in industrialized and major (large) world economies.

\section{REFERENCES}

1. Desai, M.A., Foley, C.F., and Hines, J.R., 2005. Foreign Direct Investment and Domestic Economic Activity.National Bureau of Economic Research.

2. Herzer, D., 2008. The Long-run Relationship between Outward FDI and Domestic Output: Evidence from Panel Data.Economics Letters, 100, pp.146-149.

3. Herzer, D., and Schrooten, M.,2008. Outward FDI and Domestic Investment in Two Industrialized Countries.Economics Letters, 99, pp.139-143.

4. Im, K.S., Pesaran,M.H., andShin, Y., 2003. Testing for Unit Roots in Heterogeneous Panels.Journal of Econometrics, 115, pp.53-74.

5. Johansen, S., 1988. Statistical Analysis of Cointegration Vectors, Journal of Economic. Dynamnics and Control,12, pp.231254.

6. Larsson, R., Lyhagen,J.,andLöthgren, M.,2001. Likelihood-Based CointegrationTests in Heterogeneous Panels. Econometrics Journal, 4, pp.109-142.

7. Levin, A.T., Lin, C.-f.J.,andChu, C.-s.J., 2002. Unit Root Tests in Panel Data : Asymptotic and Finite-Sample Properties. Journal of Econometrics, 108, pp.1-24.

8. Liu, X., Burridge, P.,and Sinclair, P.J.N., 2002. Relationships between Economic Growth, Foreign Direct Investment and Trade: Evidence from China. Applied Econonmic, 34, pp.1433-1440.

9. Pedroni, P., 1999. Critical Values for Cointegration Tests in Heterogeneous Panels With Multiple Regressors. Oxford Bulletin of Economics and Statistics, 61, pp.653-670.

10. Zhang, K.H., 2001. Does Foreign Direct Investment Promote Economic Growth? Evidence from East Asia and Latin America. Contemporary Economic Policy, 19, pp.175-185. 
